\title{
Systems-based approach to examine the cytokine responses in primary mouse lung macrophages infected with low pathogenic avian Influenza virus circulating in South
} East Asia

\author{
Biruhalem Taye ${ }^{1,2,3}$, Hui Chen ${ }^{2,8}$, Myint Zu Myaing ${ }^{2}$, Boon Huan Tan ${ }^{4,5}$, Sebastian Maurer-Stroh ${ }^{1,6,7}$ \\ and Richard J. Sugrue $2^{2^{*}}$
}

\begin{abstract}
Background: Influenza A virus (IAV) is a major public health concern, being responsible for the death of approximately half a million people each year. Zoonotic transmissions of the virus from swine and avian origin have occurred in the past, and can potentially lead to the emgergence of new IAV stains in future pandemics. Pulmonary macrophages have been implicated in disease severity in the lower airway, and understanding the host response of macrophages infected with avian influenza viruses should provide new therapeutic strategies.

Results: We used a systems-based approach to investigate the transcriptome response of primary murine lung macrophages (PMФ) infected with the mouse-adapted H1N1/WSN virus and low pathogenic avian influenza (LPAl) viruses H5N2 and H5N3. The results showed that the LPAI viruses H5N2 and H5N3 can infect PMФ with similar efficiency to the H1N1/WSN virus. While all viruses induced antiviral responses, the H5N3 virus infection resulted in higher expression levels of cytokines and chemokines associated with inflammatory responses.

Conclusions: The LPAI H5N2 and H5N3 viruses are able to infect murine lung macrophages. However, the H5N3 virus was associated with increased expression of pro-inflammatory mediators. Although the H5N3 virus it is capable of inducing high levels of cytokines that are associated with inflammation, this property is distinct from its inability to efficiently replicate in a mammalian host.
\end{abstract}

Keywords: Macrophages, Avian influenza virus, H5N2, H5N3, Inflammatory response

\section{Background}

Influenza A virus (IAV) represents one of the most important biological threats to human health and the global economy [1-3]. It causes yearly seasonal epidemics and periodic pandemics [4]. Seasonal influenza is estimated to be the cause up to 5 million severe cases and approximately 500,000 deaths each year. There have been four previous influenza virus pandemics, which have been collectively responsible for the deaths of more than 50

\footnotetext{
* Correspondence: RJSUGRUE@ntu.edu.sg

${ }^{2}$ School of Biological Science, Nanyang Technological University, 60 Nanyang Drive, Singapore 637551, Republic of Singapore

Full list of author information is available at the end of the article
}

million people [5-7]. The combination of drug resistance, adverse side effects and financial costs of drug and vaccine development are significant challenges in the prevention of the disease due to newly emerging influenza virus strains $[8,9]$.

IAV normally circulates in wild birds, but it can also infect domestic poultry, pigs, cats, dogs, horses, bats and humans. Although direct zoonotic transmission to humans is not common, interspecies transmission from swine and avian to humans can occurr, and zoonotic transmission can contribute to the emergence of new pandemic viruses [10-12]. Based on disease severity in birds, avian IAV can be classified as either being low 
pathogenic avian influenza (LPAI) (exhibit mild disease symptoms) or highly pathogenic avian influenza (HPAI) (exhibit severe disease symptoms). Influenza A subtypes H5N1, H7N7, H7N3 have been mostly classified as HPAI, while H5N2, H5N3, H9N2, H7N2, H7N9 and H7N10 are commonly identified as LPAI. However, both the LPAI and HPAI can infect humans with varying degrees of disease severity $[13,14]$. The morbidities and mortality from HPAI H5N1 since 2003 [15] and LPAI H7N9 since 2013 [16] are examples of severe human disease caused by avian influenza viruses.

Although the mechanisms underlying the transformation of LPAI to HPAI is not always clear, evidence suggests that this is a multifactorial process involving the acquisition of specific sequence motifs in several virus proteins e.g. the polybasic cleavage site in the hemagglutinin (HA) protein [17]. However, there are several instances where the conversion of LPAI to HPAI is not associated with the acquisition of these classical sequence motifs [18], and the mechanisms that lead to transformation into HPAI are poorly understood. Increased pro-inflammatory cytokine expression in the lower airway during influenza virus infection is an important correlate of virus pathogenicity however the mechanism by which specific virus strains induce high levels of pro-inflammatory cytokines expression is not well understood. Since avian species are an important reservoir of influenza viruses, increased understanding of the biological properties of LPAI that are circulating in the natural environment is a prerequisite to understand the risk that they pose in both human and animal disease.

The murine model of influenza virus infection is commonly used to study the transmission, host adaptation, immune responses and pathogenesis of IAVs (reviewed in [19]). However, many human and avian IAVs are not intrinsically pathogenic in mice; hence the virus has to be adapted to the murine host to allow efficient virus replication [19]. Although the mode of species adaption is not fully understood, the available evidence suggests that it involves several factors (e.g. optimization of receptor binding specificity of the hemagglutinin (HA) protein and adaptation of the virus polymerase complex) to allow replication in the cells lining the upper and lower airway [20-22]). Therefore, adaptation of LPAI viruses to a new host involves the introduction of new genetic changes that may mask inherent biological properties of these viruses [23]. The initial sites for IAV infection are the epithelial cells that line the upper respiratory tract (URT), but disease severity is associated with replication in the lower respiratory tract (LRT), and this involves other cell types including the lung resident macrophages [24]. Therefore, the capacity of influenza viruses to cause disease in the animal models depends on their capacity to replicate in the airway cells lining the URT prior to LRT. This biological property is distinct from the capacity of viruses to induce pro-inflammatory cytokines. The analysis of LPAI infection in immune cells isolated from the lung tissue allows us to examine the biological properties of the avian viruses without the prerequisite for productive infection in the upper airway of the mouse.

Macrophages play an important role in disease progression following influenza virus infection, and the host response in macrophage cells following virus infection are important determinants of disease severity. The biological properties of different macrophages are dependent on their tissue location, and macrophages that are resident in the lung exhibit subtle differences in their biological properties when compared to the macrophages resident in other tissues. At least three categories of lung-resident macrophage cells have been described, and are referred to as alveolar, interstitial and exudate macrophages. Additionally, macrophages can be changed from quiescent to activated states in response to external cues, which include cytokines (e.g. IFN $\gamma, I L-4, I L-13, T G F \beta)$, microbes and their products (e.g. LPS), growth factors (e.g. GSF-1 and GM-CSF) and other modulators (e.g. phagocytosis following bacterial and viral infections) [24]. Depending on host homeostasis signals and external environment challenges, macrophages present heterogeneous functions such as the release of reactive toxic species, production of pro/anti-inflammatory cytokines and lipid mediators, tissue remodeling clearance of apoptotic cells and oxidized lipoproteins, wound healing and regeneration [24-26]. The interaction between different IAVs and macrophages varies, and the host response to infection is largely virus isolate-specific [2729]. In this context, there are marked differences in the ability of different virus strains to induce macrophagerelated inflammatory mediators, but the mechanisms responsible for this variation are largely unknown. Understanding the molecular mechanisms by which different IAV can induce pro-inflammatory cytokines in virus-infected macrophages may allow the development of therapeutic strategies that can mitigate IAV infection. In addition, this may lead to a better understanding of how viruses that are circulating in the natural environment attain these biological properties, and if they can transfer these properties to other circulating viruses (e.g. by gene reassortment).

We have previously described the biological properties of several LPAI viruses that were isolated from imported live poultry during routine surveillance, which included H5N2, H5N3 and H9N2 viruses [30, 31]. We had concluded that these viruses were representative of LPAI viruses that are circulating in ducks within the SE Asia region. In this current study, we have extended our 
previous findings on these LPAI viruses and have applied a system-based approach to investigate the host response to these viruses in murine lung macrophages.

\section{Results}

Primary murine lung macrophages (PMФ) are infected with all the three IAV examined

We have previously demonstrated that murine alveolar macrophages (AMФ) and РMФ that were isolated from $\mathrm{BALB} / \mathrm{c}$ mice exhibited similar cytokine induction patterns during respiratory syncytial virus (RSV) infection [32]. Due to logistical issues in obtaining sufficient numbers of AMФ cells from the mice lungs for the microarray analysis, in this analysis, РМФ cells isolated from lung tissue were used. The РМФ were isolated from mouse whole lung tissue as described previously [32], and FACS analysis of anti-CD11b and anti-F4/80 stained PMФ cell preparation cells showed that greater than $95 \%$ of the cell population were $\mathrm{CD} 11 \mathrm{~b}+/ \mathrm{F} 4 / 80+$ (Additional file 1: Figure
S1A, B). The cells were either mock-infected or infected with each virus using a multiplicity of infection (MOI) of 5. After 24 hours post-infection (hpi) the cells were stained using anti-NP (detects the IAV nucleoprotein (NP)), and visualized using immunofluorescence microscopy (Fig. 1a, b, c). This indicated that in each infected cell assay $>95 \%$ of PMФ showed anti-NP staining, and confirmed similar levels of infection with each of the three viruses.

\section{Global changes in host gene expressions at 24 hours post-infection}

In the Affymetrix microarray system (GeneChip Mouse Genome 4302.0 Array) there are 28,974 annotated genes, and analysis of the microarray data indicated that $89.8 \%$ $(25,886), 89.8 \%(25,886), 89.7 \%(25,850)$ and $84.6 \%(24,368)$ of the annotated genes were expressed in H1N1/WSN, mock-infected cells, H5N2 and H5N3 virus-infected cells respectively. The global gene expression in РМФ infected

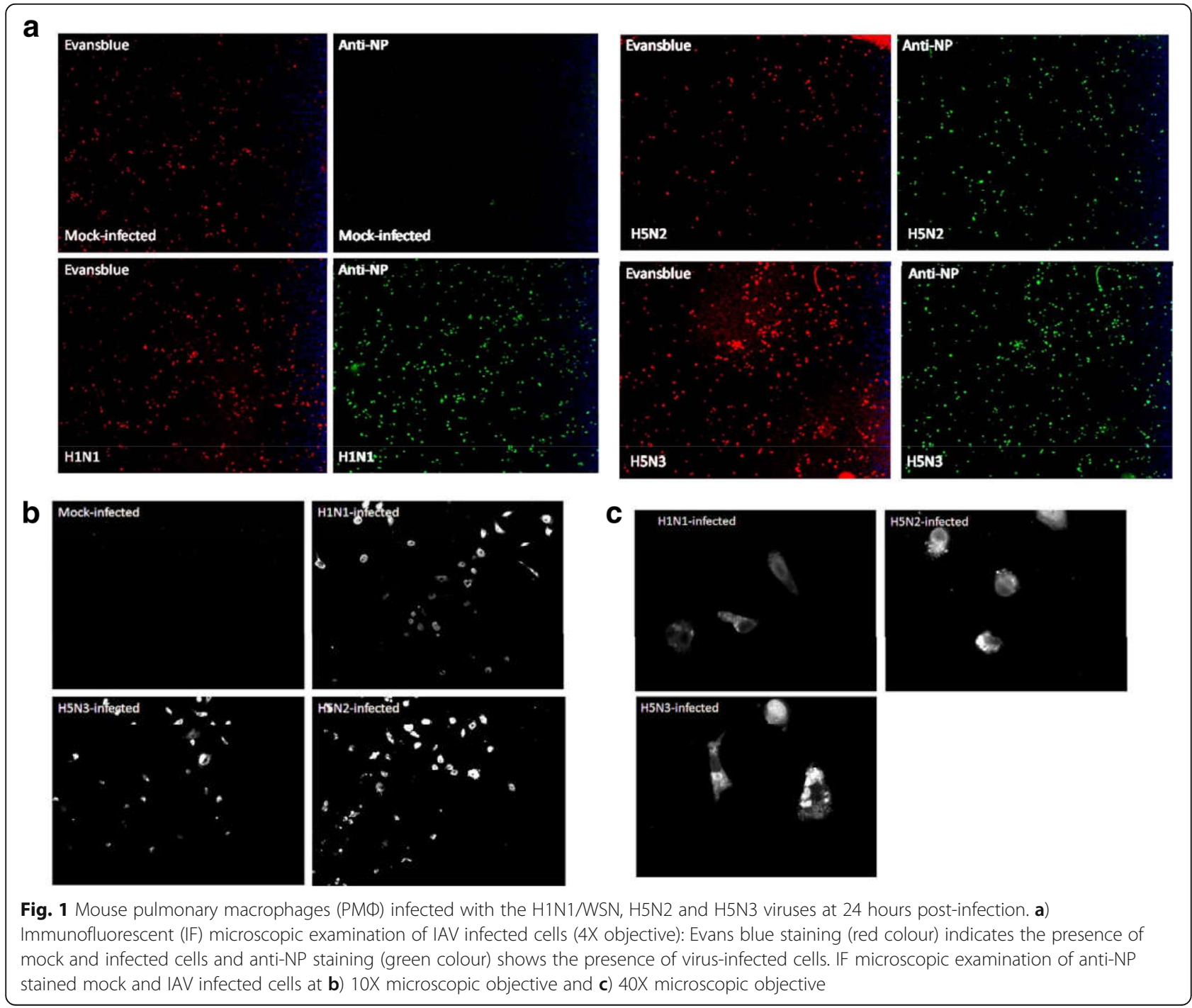


with each of the three viruses was examined at $24 \mathrm{hpi}$. Overall, 1830 probe sets (1103 genes) were differentially expressed in at least one of the virus infections at $24 \mathrm{hpi}$ (Additional file 2). The numbers of differentially expressed genes (DEGs) at 24 hpi in H1N1/WSN, H5N2, and H5N3 virus-infected cells were 193, 21 and 1071 respectively (Fig. 2a). The numbers of up- and down-regulated genes are 3.9 and 10.4 times higher in $\mathrm{H} 5 \mathrm{~N} 3$ virus-infected cells than H1N1/WSN virus-infected cells. There are no significantly up-regulated genes in cells infected with the H5N2 virus, and the down-regulated genes in cells infected with the $\mathrm{H} 5 \mathrm{~N} 3$ virus were 23.8 times higher than in H5N2 virus-infected cells. The number of DEGs with $\left|\log ^{\mathrm{FC}}\right|$ value $>3$ are also higher following $\mathrm{H} 5 \mathrm{~N} 3$ virus infection (Fig. 2b (i and ii)).

Overlap analysis of DEGs at 24 hpi is shown in Fig. 2c. One hundred thirty-two (91.6\%) (132/144) of the genes showing up-regulated expression in cells infected with the $\mathrm{H} 1 \mathrm{~N} 1 / \mathrm{WSN}$ virus were shared with the H5N3 virusinfected cells. The up-regulated shared genes include APOL9A, CCL12, CMPK2, DHX58, H28, IFI44, IFIT1, IFIT2, IFIT3, ISG15, MX1, OAS1A, OASL2, RSAD2,

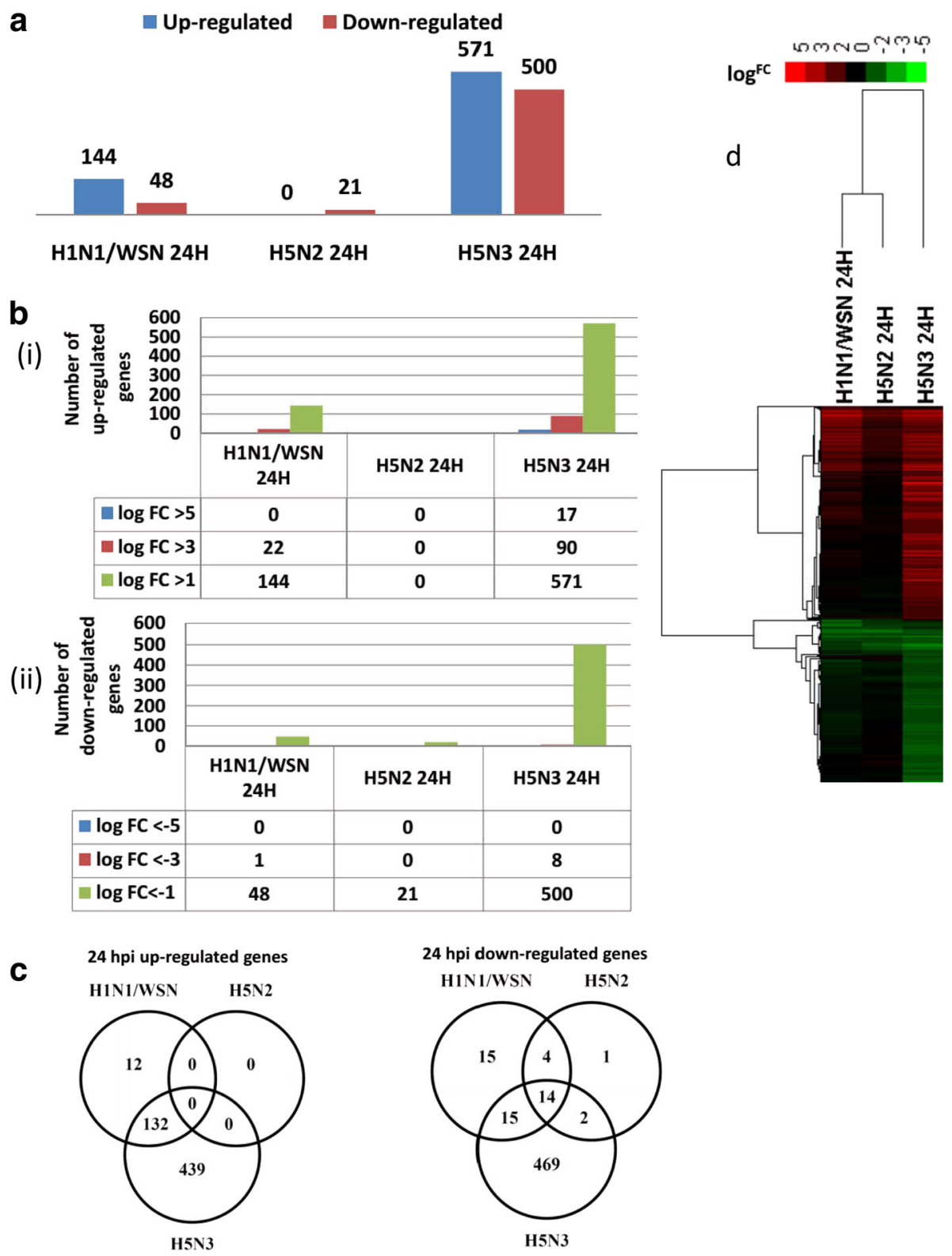

Fig. 2 Global host gene expression in mouse PMФ infected with IAVs at 24 hours-post infection (24H): a) Number of up-and down-regulated genes $\mathbf{b}$ ) the extent of up-and down-regulated genes with $\log ^{F C}$ values i) up-regulated genes ii) down-regulated genes c) Overlap analysis of DEGs in three IAV infections d) unsupervised hierarchical clustering of DEGs 
RTP4, SLFN3, USP18, XAF1, and ZBP1. These genes are associated with innate immune response to viral infection and were up-regulated in different IAV strains (H1N1, H3N2, H5N1, H5N2, and H7N1) in A549 cells [33], human blood, PBMC, and primary epithelial cells [34]. These genes (e.g. IFI44, IFIT1, OAS1A, OASL2, and XAF1) were also implicated in response to other respiratory viruses (RSV and HRV) in human PBMC and lung epithelial cells [33].

Similarly, most $(76.2 \%$ of the $\mathrm{H} 5 \mathrm{~N} 2$ virus and $60.4 \%$ of the H1N1/WSN virus) down-regulated genes were shared with the H5N3 virus down-regulated genes. Fourteen down-regulated genes were shared between the three viruses, among which AGER, SFTPD, EGFL6, NDNF, DSP and TTN were involved in regulation of cell adhesion and wound healing (Fig. 2c). Approximately 76.8\% (439/571) up-regulated and 93.8\% (469/500) down- regulated genes were unique to $\mathrm{H} 5 \mathrm{~N} 3$ infection (Fig. 2c). The hierarchical clustering of DEGs/probe sets at $24 \mathrm{hpi}$ for the three viruses was illustrated in Fig. 2d. In H5N3 virusinfected cells there are unique up-regulated and downregulated gene cluster patterns, which wasconsistent with the higher proportion of unique up-and downregulated genes shown in Fig. 2c. Collectively, the data showed that LPAI viruses induce few common gene expression signatures compared to other IAV isolates and other respiratory viruses, suggesting that most of the DEGs were strain-specific expression signatures.

\section{Functional annotation of DEGs}

Functional annotations of the DEGs i.e. GO biological process and KEGG pathway was analyzed using Metascape (http://metascape.org/gp/index.html\#/main/step1) [35]. We compared significantly enriched pathways and their enrichment p-values (q-value) for all the viruses at $24 \mathrm{hpi}$. The top 20 statistically significant pathways (q-value $<0.05$ ) are described in Fig. 3a. Generally, the pathways are related to immune responses (cytokines, interferons and inflammatory responses), morphogenesis and cell migration (Fig. 3a). Separate pathway enrichment analysis for the up-regulated genes (Fig. 3b) and down-regulated genes (Fig.3c) indicated that the cytokine, interferon and inflammatory responses were enriched in the upregulated genes, while the enrichment of down-regulated genes were associated with cell migration, morphogenesis and metabolic pathways. It was expected that infection of macrophage cells with IAVs induces immunological responses [36]. The activation of type I and II interferon pathways (Fig. 3a and b) alleviate IAV infections [37], while increased activation of cytokine responses could result in the induction of a cytokine storm (inflammatory cytokines), which are associated with immunepathological conditions [36, 37]. The H1N1/WSN and $\mathrm{H} 5 \mathrm{~N} 3$ viruses significantly induced interferon pathways
(Fig. 3a and b) and while these viruses induced inflammatory responses, these were more prominent in $\mathrm{H} 5 \mathrm{~N} 3$ virus-infected cells at $24 \mathrm{hpi}$. Increased induction of inflammatory cytokines is a characteristic of infections caused by HPAI viruses, and the induction of inflammatory pathways in $\mathrm{H} 5 \mathrm{~N} 3$ virus-infected cells could indicate its potential to induce similar pathologic-related immune conditions. Inflammatory cytokines could also disturb the normal cellular structure, morphology and migration contributing to infiltration of fluids and immune cells at the site of inflammation [38]. H5N2 virus infection showed no induction of inflammatory pathways, deregulation of pathways related to cellular growth, and pathways related to morphogenesis compared with the mouse-adapted H1N1/WSN virus at 24 hpi (Fig. 3b, c). Taken together, this data indicates that the $\mathrm{H} 5 \mathrm{~N} 2$ virus is less able to induce pathways related to inflammatory cytokines compared to the H1N1/WSN virus, while $\mathrm{H} 5 \mathrm{~N} 3$ virus induced inflammatory pathways at higher levels.

\section{Host response to the IAVs infection}

Based on the functional annotation and the extent of gene expression changes (highest $\log ^{\mathrm{FC}}$ values), we focused on genes related to cytokines, interferon and cell death and macrophage activation pathways in more detail since these have been implicated in increased virus pathogenicity. Selected genes from virus-induced expression changes were also validated by biochemical cytokine assay.

\section{IAV induced cytokines}

Infections with the H1N1/WSN and H5N3 viruses induce expression of several cytokine genes in PMФ (Fig. 4a). As indicated in Fig. 4a, the extent of cytokine gene expression following $\mathrm{H} 5 \mathrm{~N} 3$ virus infection is higher than in cells infected with the H1N1/WSN and H5N2 viruses. To validate the gene expression changes; we examined the cytokine and chemokine response of PMФ in $\mathrm{H} 1 \mathrm{~N} 1 / \mathrm{WSN}, \mathrm{H} 5 \mathrm{~N} 2$ and $\mathrm{H} 5 \mathrm{~N} 3$ virus-infected cells by measuring the cytokine protein levels at 4, 8 and $20 \mathrm{hpi}$. In addition, we examined another H9N2 LPAI virus that was also isolated from poultry imported into Singapore, and whose biological properties have been examined in cell lines [39]. We observed increased level of inflammatory mediators $(I L-1 \alpha, I L-1 \beta, I L-6, M I P-1 \alpha$ (CCL3), MIP$1 \beta$ (CCL4), RANTES (CCL5), MCP-1 (CCL2)) following H5N3 virus infection at 4, 8 and 20 hpi compared to cells infected with the H1N1/WSN, H5N2 and H9N2 viruses (Fig. 4b). The cytokine levels measured was consistent with the cytokine gene expression profile, which also provides validation of the gene expression analysis. In cells infected with the H5N3 virus the levels of cytokine gene expression was significantly higher than in cells infected with either the H1N1/WSN or H5N2 viruses 


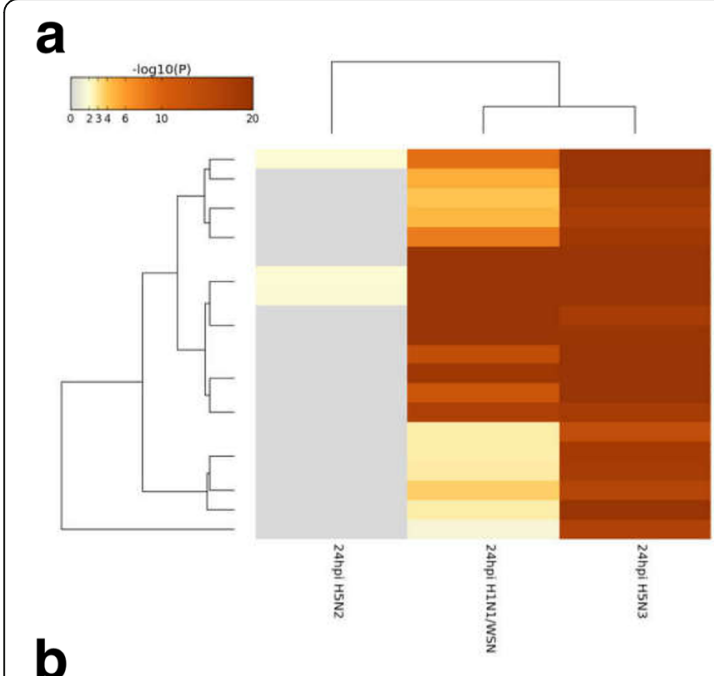

O:0006954: inflammatory response

:0002683: negative regulation of immune system process

GO:1901701: cellular response to oxygen-containing compound

mmu04668: TNF signaling pathway

GO:0045087: innate immune response

GO:0034097: response to cytokine

GO:0002252: immune effector process

GO:0035456: response to interferon-beta

GO:0009615: response to virus

GO:0001816: cytokine production

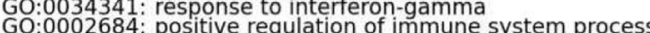

ko0 5168 . Herpes simplex infection

GO:0010942: positive regulation of cell death

GO:1903555: requlation of tumor necrosis factor superfamily cytokine production GO:0001906: cell killing

GO:0031348: negative regulation of defense response

GO:1902533: positive regulation of intracellular signal transduction

b

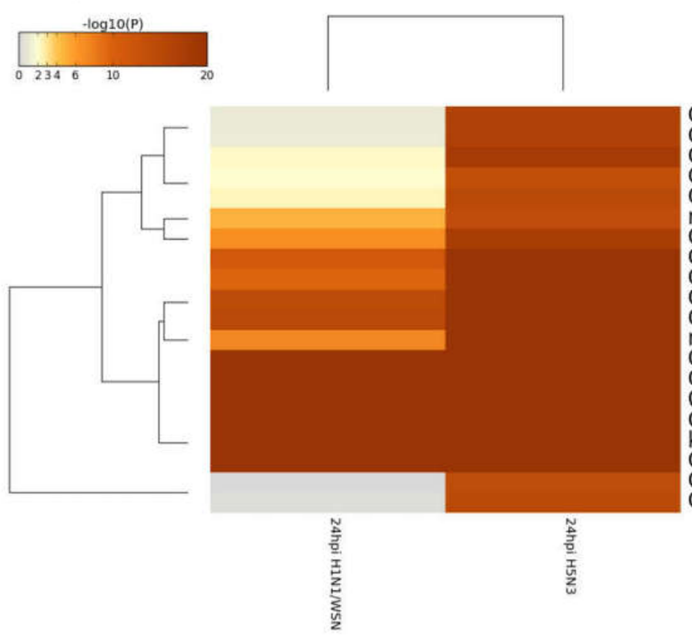

GO:1903555: regulation of tumor necrosis factor superfamily cytokine production GO:0019882: antigen processing and presentation

GO:0072593: reactive oxygen species metabolic process

GO:0042107: cytokine metabolic process

GO:0002683: negative regulation of immune system process

mmu04620: Toll-like receptor signaling pathway

GO:0001562: response to protozoan

GO:0001816: cytokine production

GO:0060326: cell chemotaxis

GO:0002684: positive regulation of immune system process

GO:0031347: regulation of defense response

mmu04668: TNF signaling pathway

GO:0009615: response to virus

:0034097: response to cytokine

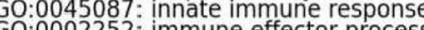

0.002.

G0:0035456: response to interferon beta

G0:005631: alpha-beta T cell activation

GO:1902533: positive regulation of intracellular signal transduction

C

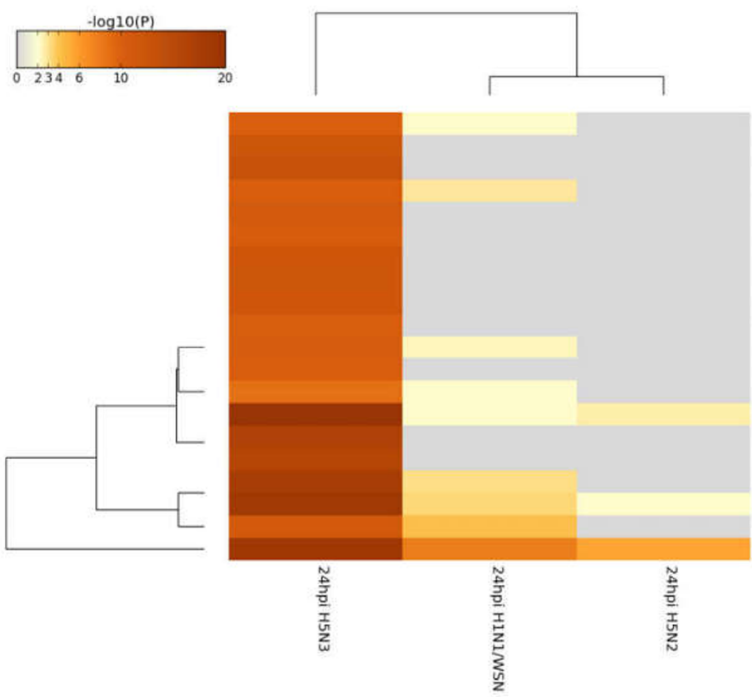

GO:0000902: cell morphogenesis

GO:0071248: cellular response to metal ion

GO:0002684: positive regulation of immune system process GO:0051050: positive regulation of transport GO:0042060: wound healing GO:0048771: tissue remodeling mmu05410: Hypertrophic cardiomyopathy (HCM) GO:0042326: negative regulation of phosphorylation GO:0050873: brown fat cell differentiation GO:1902533: positive regulation of intracellular signal transduction mmu04142: Lysosome

GO:0060548: negative regulation of cell death

GO:0061061: muscle structure development

GO:0032101: regulation of response to external stimulus GO:000309: skeletal muscle contraction

GO:0001775: cell activation

GO:0051270: regulation of cellular component movement GO:0008285: negative regulation of cell proliferation GO:0003012: muscle system process

Fig. 3 (See legend on next page.) 
(See figure on previous page.)

Fig. 3 Top 20 statistically significant $(q<0.05)$ functionally enriched pathways or/and GO biological process (GBP) of the DEGs at 24 hours postinfection (hpi):: a) Pathways/GBP from both up- and down-regulated genes. b) Pathways/GBP from up-regulated genes c) Pathways/GBP from down-regulated genes. Increased

intensity of the colour shows increased significance of the pathway/GBP corresponding to each virus infection conditions. More related pathways/GBP were clustered together (left) and the viruses inducing similar pathways/GBP are clustered together (top)

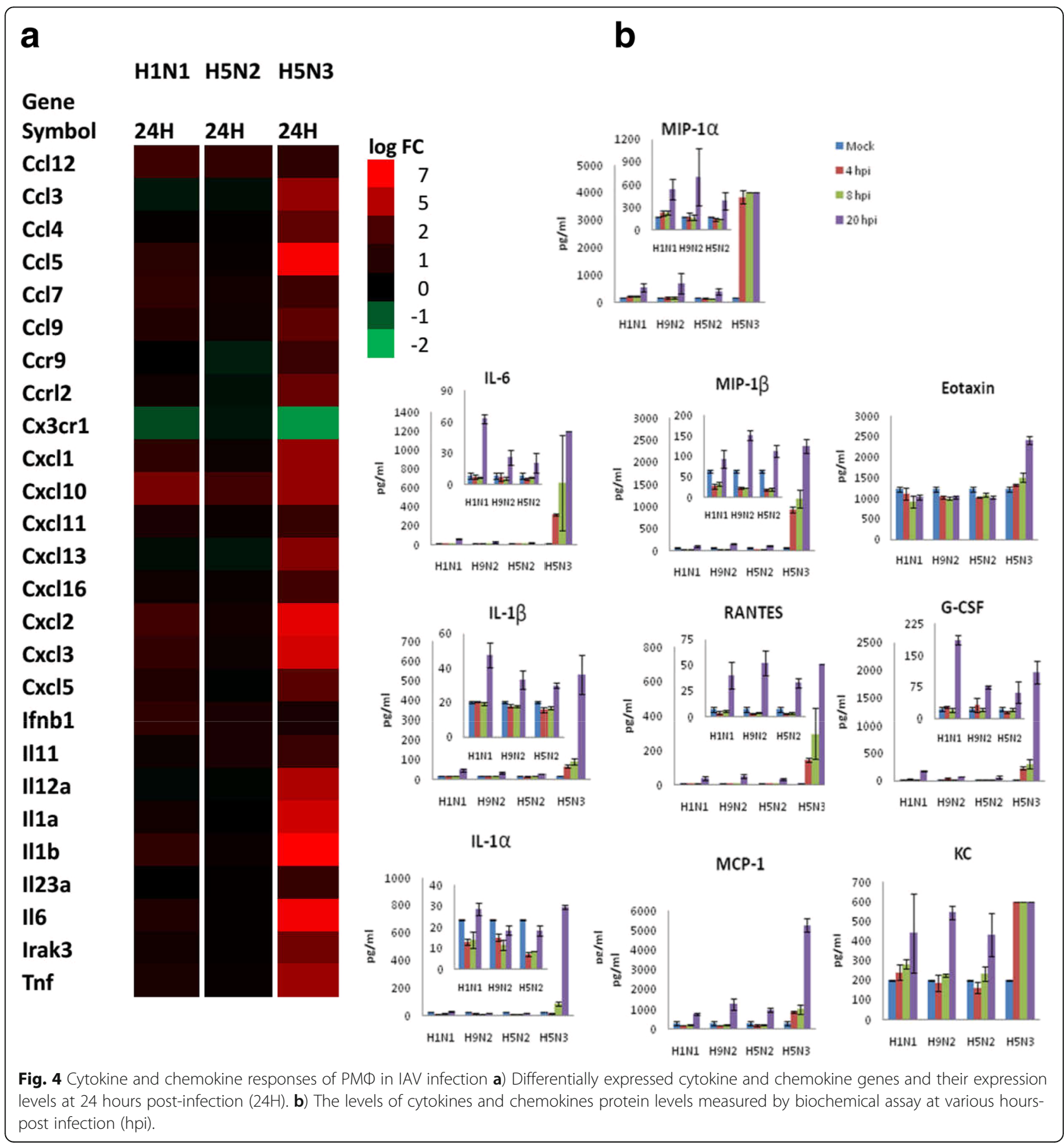


(Additional file 2). At the protein level, the cytokines in H5N3 virus infection are also 2.3 to 27 times, 2.3 to 48 times and 3.3 to 40 times higher compared to H1N1/ WSN, H5N2 and $\mathrm{H} 9 \mathrm{~N} 2$ virus infection respectively (Fig. 4b). In contrast, the expression of cytokines that are important for the survival of macrophages was down-regulated in H1N1/WSN and H5N3 virus-infected cells at 24 hpi (Fig. 4a) [40]. Taken together, inflammatory chemokines and cytokines are highly induced in H5N3 virus-infected cells, compared with cells infected with the H1N1/WSN, H5N2 and H9N2 viruses.

\section{Interferon stimulated genes (ISGs) and cell death}

Virus infections are first recognized by the pattern recognition receptors of the host cell, and subsequently induce activation of IRFs and production of interferon $(I F N)$. This can be followed by transcription of many antiviral ISGs [41]. The ISGs have several cellular effects, which include anti-viral, immuno-modulation, anti-angiogenic, cell cycle arrest and anti-apoptotic functions [42]. As expected, several of the ISGs were induced in РМФ upon infection with the H1N1/WSN and $\mathrm{H} 5 \mathrm{~N} 3$ viruses (Fig. 5a). Unlike the higher expression of cytokine responses in $\mathrm{H} 5 \mathrm{~N} 3$ virus infection, generally the extent of ISGs expression were similar in H1N1/WSN and H5N3 virus infection (Fig. 5a). However, certain ISGs (e.g. guanylate binding protein 1, 2, 3 and 6 (GBP1, 2, 3 and 6)) have higher expression levels following infection with the $\mathrm{H} 5 \mathrm{~N} 3$ virus than the other two isolates (Fig. 5a). GBP1, GBP2 and GBP3 have antiviral activity against IAV [43] and can also be activated by inflammatory cytokines [44]. IFIT1 is significantly expressed in both $\mathrm{H} 1 \mathrm{~N} 1 / \mathrm{WSN}$ and $\mathrm{H} 5 \mathrm{~N} 3$ virus-infected cells. It is an antiviral protein for viruses that bear 5 '-triphosphate RNA [45], however recently it was reported to have no effect on negative sense RNA viruses including influenza [46]. Raw264.7 cells pre-treated with $T N F \alpha$ presented with an elevated level of IFIT1 induced cell death [47]. In line with this, in $\mathrm{H} 1 \mathrm{~N} 1 / \mathrm{WSN}$ and $\mathrm{H} 5 \mathrm{~N} 3$ virus infection an elevated level of IFIT1 was associated with increased expression of anti-apoptotic genes XIAP associated factor $1(X A F 1)$ in both viruses and TNF receptorassociated factor 1 (TRAF1) in $\mathrm{H} 5 \mathrm{~N} 3$ virus infection (Fig. 5a) in response to early cell death [48].

\section{Macrophage activation}

There is growing evidence that macrophages are functionally subtyped into M1 (activated by bacterial lipopolysaccharides (LPS) or IFN $\gamma$ ) and M2 (activated by IL-4, IL-13 or TGF $\beta$ ). M1 macrophages favour glycolytic metabolism, production of reactive oxygen species (ROS) and pro-inflammatory reactions, and are associated with a Th1 response which is essential to combat intracellular infections. The M2 macrophages utilize fatty acid oxidation and mitochondrial respiration and induce anti-inflammatory mediators and are linked to Th-2 response, which is important for extracellular parasitic responses, tissue remodeling, and repair and wound healing. M1 and M2 have a different metabolic profile ([24-26, 49-53]). M1 cells are characterized by overexpression of NOS2, MTOR, PFKFB3, COX2, PTGES, HIF1A, SLC2A1, G6PD, GCK and down-regulation of DHCR24, COX1, LTA4H, TBXAS1, ALOX5, and LCAT. On the other hand, M2 cells showed increased expression of ARG1, PRKAB1, PFKFB1, STAT6, COX1, ATF3, PPARA, PPARG, SDH, NRF1, ESRRA, TNFAIP812, EPAS1and low level of PTGES.

We examined if the expression changes in IAV infected РMФ lead to the formation of either of these macrophage phenotypes. The expression changes of M1/M2 associated metabolic genes indicated that H5N3 virus induces classical activation of PMФ presenting with M1 like phenotype with up-regulation of SLC2A1 and down-regulation of PPARG, ATF3 and TNFAIP812 (Fig. 5c, d). Similarly, genes associated with wound healing and tissue remodeling were down-regulated in cells following $\mathrm{H} 5 \mathrm{~N} 3$ infection (Fig. 3c). In contrast, H1N1/ WSN and $\mathrm{H} 5 \mathrm{~N} 2$ virus infection induced a M2 like phenotype, which is characterized by increased expression of arginase 1 (ARG1) at 2hpi (Fig. 5c, d) and had a similar metabolic profile as unpolarized (inactivated) macrophages (mock infected) (Figs. 3c, 5c, d) [54]. Taken together, this data suggests that while H1N1/WSN and $\mathrm{H} 5 \mathrm{~N} 2$ viruses induced M2 like activation, the $\mathrm{H} 5 \mathrm{~N} 3$ virus induces M1 phenotype macrophages.

\section{Discussion}

Influenza virus infection of alveolar epithelial cells type II (AECII) and murine lung tissue showed increased expression of cytokines (IL-6, CXCL10, CXCL5, and CXCL9) and ISGs (RSAD2, IFIT1, IFI44, IFIT2, MX1, OASL2, GBP3, IIGP1, SLNF4). Although the levels of expression differed in these studies, several of the inflammatory cytokines and interferon response were detected in both the lung and AECII transcriptome analysis [55]. Similarly, several other cell types of the lung e.g. epithelial cells type I, macrophages, dendritic cells, and mast cells contribute to inflammatory cytokines production during IAV infections [56-58]. We observed similar increases in expression of inflammatory cytokines in the $\mathrm{H} 5 \mathrm{~N} 3$ virus-infected PMФ cells.

The H5N3 virus induced higher levels of pro-inflammatory cytokine levels in mouse PMФ compared with the $\mathrm{H} 1 \mathrm{~N} 1 / \mathrm{WSN}$ and $\mathrm{H} 5 \mathrm{~N} 2$ viruses. Increased inflammatory cytokine expression in whole mouse lung tissue infected with different mouse-adapted pathogenic/virulent IAV subtypes have been described previously using a transcriptomic approach [55, 59-65]. The 2009 pandemic 


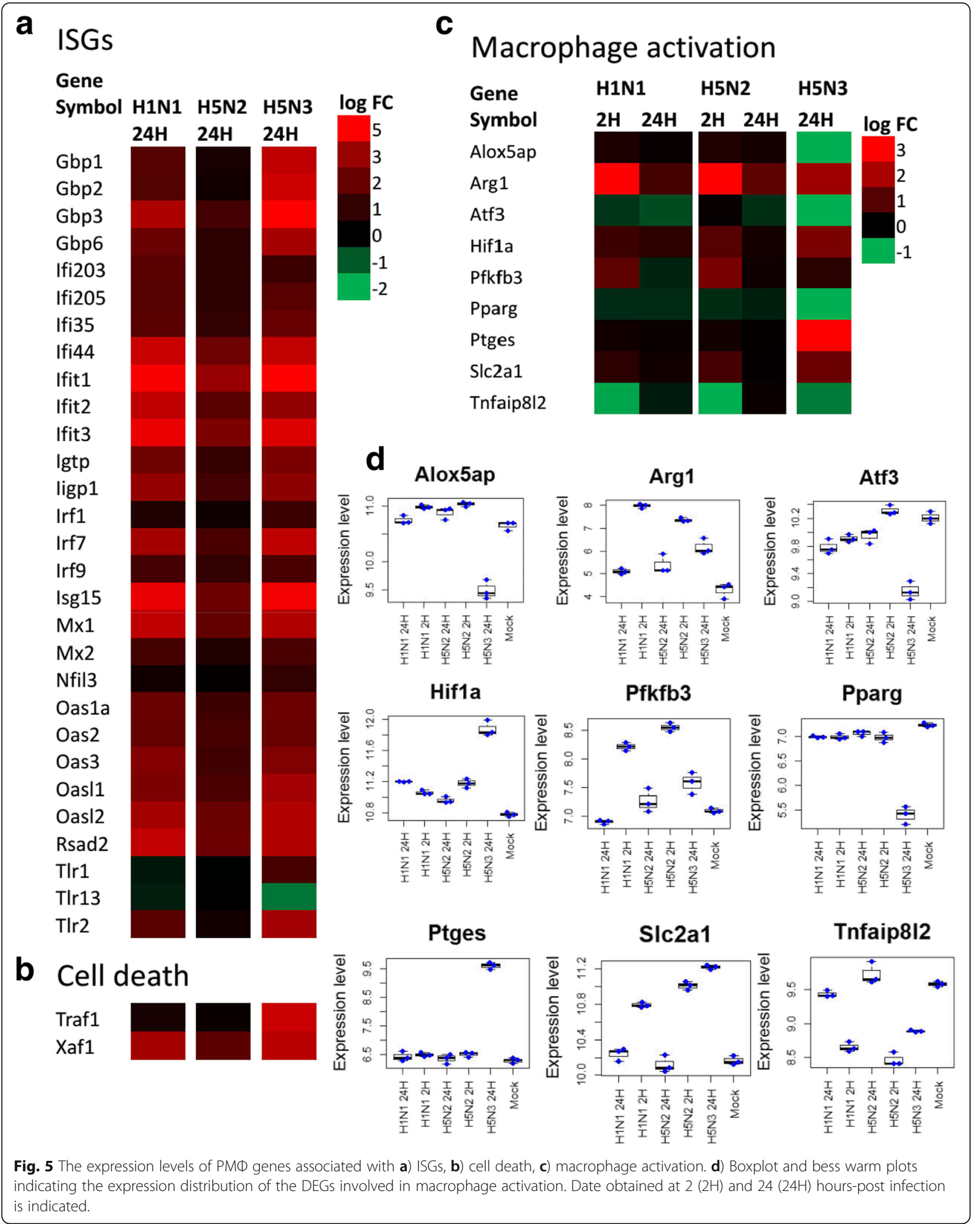


H1N1 virus induced increased expression of CXCL10, OASL, OAS2, IFIH1, USP18 and XAF1 [65]. Similarly, upregulated expression of inflammatory cytokines (CXCL10, CXCL11, CXCL9, CXCL13, CCL9, CCL5, IL-6, IL1, IL1A, $I L 1 B, T N F$, and TNF- $\alpha$ ) and ISGs (GBP2, GBP4, GTP1, ISG15, DdX58, IFIH1) were shown in virulent H3N2/ HK31 virus infections [59-61]. In addition, the lung transcriptome of HPAI H5N1 virus infection in susceptible mouse revealed increased expression of inflammatory cytokines (CCL2, CXCL2, and TNF- $\alpha, C S F 3$ ) and interferon responses (IFN- $\alpha$, IFN- $\beta$, IL28B, IFNA4, IFNA5), which were associated with increased viral load and disease severity $[62,63]$. The $\mathrm{H} 7 \mathrm{~N} 9, \mathrm{H} 7 \mathrm{~N} 7$ and $\mathrm{H} 5 \mathrm{~N} 1$ infected mouse lung transcriptome also showed higher levels of CXCL13, IL-6, IFNG, IFNB1, IRF9, IRF1, and TNF compared with 2009 pandemic H1N1 virus infections. Furthermore, increased expressions of inflammatory cytokines and decreased transcription of genes associated with lipid metabolism correlated with increased disease severity [65].

Lung-resident macrophages have been implicated in disease severity following IAV infection [27, 66]. The pathogenicity of IAVs correlated with their ability to induce high levels of pro-inflammatory cytokines in macrophages [67], which in turn is proposed to cause the increased migration of granulocytes into the lung that leads to localized tissue damage [68]. Although the association of high levels of infectious virus production and higher levels of inflammatory responses is suggested, other factors may also play a role in this process. The $\mathrm{PR} 8 / \mathrm{H} 1 \mathrm{~N} 1$ virus strain is highly virulent and was characterized by higher level of virus production and lung inflammation than HKx31/H3N2 and BJx109/ H3N2 viruses [69]. Characterization of inflammatory cell types in mice lung showed that overexpression of CCL2 and CCR2+ monocyte-derived cells (monocyte-derived dendritic cells and exudate macrophages) are the predominant cause of immune pathology during PR8/ H1N1 virus infection [70]. In addition, TRAILexpressing macrophages (exudate macrophages) are implicated in influenza-induced pneumonia through increased expression/release of TRAIL and alveolar epithelial cell (AEC) apoptosis [71]. The HPAI H5N1 virus is a potent inducer of of inflammatory mediators (e.g. IL1, IL-6, TNF $\alpha, I L-8, M C P-1, I P-10, I F N \gamma$ ) in patients, in vivo mouse model experiments and in vitro macrophage infections [67, 72-78].

Although all the three viruses infected PMФ with similar efficiency, surprisingly the H5N3 virus induced highest inflammatory responses at $24 \mathrm{hpi}$ compared to H1N1/WSN and H5N2 viruses. However, we obtained no evidence that the infection of murine macrophages with either of the viruses induced a productive infection (Sutejo, Tan and Sugrue, unpublished observations). In this context mouse macrophages infected with either of
H1N1/WSN, A/HK/483/97 H5N1 (HPAI) or A/X-31/ $\mathrm{H} 3 \mathrm{~N} 2$ viruses showed induced expression of inflammatory cytokines through activation of either $N F-K B$ or $M A P K$ signaling pathways in a strain dependent manner [79-83]. However, it was reported that a productive infection in murine-derived macrophages was characteristic of the HPAI H5N1 virus [79]. Although these studies have indicated stain-specific differences in pro-inflammatory cytokine induction in murine macrophages, it is not clear if these observations can be extrapolated to human macrophages. However, HPAI H5N1 infection lead to the expression of higher levels of inflammatory mediators than seasonal $\mathrm{H} 1 \mathrm{~N} 1$ and $\mathrm{H} 3 \mathrm{~N} 2$ viruses in human $\mathrm{AM}$ [73, 84]. Moreover, the avian viruses H5N1 and H7N9 induced higher inflammatory responses than the seasonal or $2009 \mathrm{H} 1 \mathrm{~N} 1$ pandemic viruses [67, 74, 85-90].

Interestingly, H5N3 virus-infected PMФ cells induce expression patterns and pathways (including cytokines) that are similar to the response that we have observed in RSVinfected PMФ cells (Additional file 1: Figure S1C, D; Additional file 2) [32]. RSV is another important virus that can cause lung tissue damage via pro-inflammatory cytokine induction in the lower airway. Therefore comparing the cellular response to these viruses may give insights into the interaction that these viruses with macrophages, and possibly the induction of common pathways that may be activated during virus infection that leads to inflammation. We compared the DEGs in this study with DEGs of PMФ in response to RSV infection from our previously published work [32]. Overlap analysis of the up-regulated genes in IAVs infection with RSV indicated 465 (277 upregulated and 188 down-regulated), 102 (100 upregulated and 2 down-regulated) genes shared in H5N3 and H1N1/WSN virus infected cells respectively (Additional file 1: Figure S1C), indicating, higher numbers of DEGs shared between RSV and the H5N3 virus than with the H1N1/WSN and H5N2 viruses. The severe form of diseases due to RSV infection is associated with increased level of inflammatory cytokines and chemokines (TNF $\alpha$, $I L-1 \alpha \beta, C X C L 8, C X C L 10, C C L 5, I L 6, C C L 2$ and CCL3) production by epithelial cells and macrophages (reviewed in $[91,92])$. Similarly, RSV-infected PMФ showed an elevated level of these inflammatory mediators [32]. The levels of either gene expression or cytokine proteins (IL-1 $\alpha, T N F \alpha, I L-6, C X C L 10, C C L 5, C C L 2, C C L 3, C C L 4$, and CCL5) in RSV-infected PM $\Phi$ are comparable to the H5N3 virus infection (Additional file 2). This suggests that the H5N3 LPAI virus and RSV could share common features in the way that they interact with the macrophages.

Since the murine macrophage cells were equally susceptible to infection with each of the three viruses these differences cannot be explained by reduced infections rates. The $\mathrm{H} 5 \mathrm{~N} 3$ virus internal genes have been shown 
to share common ancestry with different subtypes of avian viruses circulating in different geographical locations and environment [31]. This previous analysis revealed a high level of sequence conservation between the H5N3 and H5N2 viruses. However, we can hypothesize that small changes in gene sequences may be sufficient to account for the significant differences in the host responses to infection. Although the H1N1/WSN virus was able to replicate efficiently in BALB/c mice, the $\mathrm{H} 5 \mathrm{~N} 2$ and $\mathrm{H} 5 \mathrm{~N} 3$ viruses replicated poorly in the mouse infection model (Yeo, Tan and Sugrue, unpublished observations). This is consistent with the expected low efficiency of infection of these avian viruses in mammalian hosts, including humans, and highlights a limitation in the mouse model when examining the interaction of host response in murine macrophages. The capacity of the H5N3 virus to induce pro-inflammatory cytokines in macrophages is therefore a property of the virus that is distinct from its capacity to replicate in non-avian cell types. We have no evidence that this biological property is unique to the H5N3 virus examined in this study, and it is possible that the capacity to induce high levels of cytokines may also be a property of other circulating LPAI viruses. The expected low replication rates in non-avian hosts may normally mitigate this intrinsic biological property of such viruses. However, we can speculate that in the natural environment such viruses (e.g. the H5N3 virus) could transfer their property of inducing high levels of pro-inflammatory cytokines to another virus that replicates better in mammals. Assuming that such a reassorted virus would be viable in the natural environment, this could result in inherent biological changes with medically important implications. It is therefore, necessary to understand this process more completely, and identify sequence motifs that may correlate with this biological property (e.g. using the FluSurver platform: http://flusurver.bii.astar.edu.sg). This information would be of use in surveillance studies which would allow the threat of circulating viruses to be better assessed.

The complete mechanism of avian IAV adaptation and pathogenicity to mammalian hosts is not well understood yet. However, it is likely that it involves the HA protein receptor binding specificity and polymerase complex activity [93]. In terms of key host specificity markers like HA 226 (Q avian, L mammalian, H3-based numbering) and PB2 627 (E avian, $\mathrm{K}$ mammalian), the H5N3 virus strain studied here still has the avianpreferred residues in both cases. Interestingly, the HA does have one S159N mutation that has been implicated in increased binding to mammalian-type 2,6 receptors without loss of binding to avian-like 2,3 [94]. However, the same mutation is also found in the $\mathrm{H} 5 \mathrm{~N} 2$ virus strain used in this study so it cannot be held responsible for the observed differences. On the other hand, we have found a K615R mutation in the PA protein of the $\mathrm{H} 5 \mathrm{~N} 3$ virus isolate, but not in the $\mathrm{H} 5 \mathrm{~N} 2$ and $\mathrm{H} 9 \mathrm{~N} 2$ viruses used in our study. Combination of mutations in internal genes, including PA 615R, has been suggested to contribute to the virulence of avian viruses in mammalian hosts [95]

Under normal circumstance, a cell has its own inherent metabolic activity that is responsible for a variety of different physiological processes. Increasing evidence suggests that metabolism under the influence of specific stimuli (e.g. virus infection) is an important determinant for functional phenotype differences in macrophages [50]. There are two mechanistic options to connect macrophages and metabolism, i.e. either the macrophage cell can regulate metabolic function extrinsically, or intrinsic metabolic functions dictates macrophage activation states [50]. The current study demonstrated increased expression of $A R G 1$ in $\mathrm{H} 1 \mathrm{~N} 1$ and $\mathrm{H} 5 \mathrm{~N} 2$ virus-infected PMФ at 2hpi. In M2 activated macrophages increased expression of ARG1 catalyzes polyamine production, which is essential for the synthesis of collagen, tissue remodeling and cell proliferation [51]. In line with this, following H1N1/WSN and $\mathrm{H} 5 \mathrm{~N} 2$ virus infection there is a remarkable change in the maintaining of the down-regulated pathways that were associated with cell proliferation and cellular organization from 2hpi to 24hpi (Fig. 3c, Additional file 1: Figure S1E). In contrast, M1 macrophages are characterized by increased expression of NOS2 and NO production. The subsequent induction of $N F-k B$ mediated inflammatory mediators (TNF- $\alpha, I L-6, I L-12, \mathrm{NO}$ and others) leads to tissue inflammation and cell death. In addition, the M1 macrophages reprogram glucose metabolism to the glycolytic pathway and the pentose phosphate pathway (PPP), which results in the production of reactive oxygen species (ROS) that mediate tissue disruption [51]. Similarly, the current study revealed that the $\mathrm{H} 5 \mathrm{~N} 3$ virus activated the PMФ into a M1 phenotype which is characterised by increased expression of NF- $k B$ mediated inflammatory cytokines and down-regulation expression of pathways related to proliferation and myogenesis. Although the effect of different IAV strains in activation of different macrophages subtypes is not well understood, recently Zhao et al., 2014 suggested that activation of macrophages into M1/M2 phenotype is time and macrophage type dependent [96]. Continuous activation of macrophages into the M1 phenotype is associated with severe disease, while the M2 phenotype is an indication of recovery from disease/infection [96].

This analysis demonstrates that LPAI viruses interact with immune-related cells in a virus-specific manner, leading to virus stain-specific changes in pro-inflammatory cytokine expression. The capacity of the avian H5N3 virus to infect mammalian host cells and result in increased expression of inflammatory mediators suggests that this is a 
unique property that is distinct from other factors, e.g. virus replication in mammals. Since in the natural environment the $\mathrm{H} 5 \mathrm{~N} 3$ virus can potentially reassort with other circulating influenza viruses, and if such virus is viable this may be able to transfer unique properties that are associated with increased cytokine induction. The identification of sequence motifs in the $\mathrm{H} 5 \mathrm{~N} 3$ virus that is associated with the increased cytokine induction will be the subject of future studies. This information will allow the identification of sequence motifs that can be used in surveillance studies to assess LPAI viruses which could impose threats to human health in the future.

\section{Conclusion}

The H5N2 and H5N3 LPAI viruses can infect PMФ similarly to the mouse-adapted H1N1/WSN virus. The global and temporal host gene expression indicated that while there were comparable expression levels of ISG in H1N1/WSN and H5N3 virus-infected cells, increased pro-inflammatory responses were associated with H5N3 virus infection. This systems-based approach provides evidence that increased cytokine induction during influenza virus infection is not a property that is unique to HPAI viruses, but it is also an inherent property of some LPAI viruses. A better understanding of the signals in LPAI viruses that induce host responses to infection should provide insights into the molecular mechanism of pathogenesis. It will also allow a better understanding of the contribution that these viruses play in the emergence of novel influenza strains in epidemics and pandemics.

\section{Methods}

Virus, tissue culture and antibodies

H1N1/WSN virus (A/WSN/1933(V-1520)) was purchased from American Type Culture Collection (ATCC). The LPAI isolates H5N2/F118 (A/Duck/Malaysia/F118/2004), H5N3 (A/Duck/Singapore-Q/F119/1997) and H9N2 (A/ Duck/Malaysia/02/2001) viruses were obtained from AgriFood and Veterinary authority of Singapore and have been characterized previously [31]. The 9 to 11-day old embryonated chicken eggs were used for virus stock preparation, and TCID50 in MDCK (standard plaque assay) was performed to measure the infectivity of the viruses. РМФ $(\mathrm{CD} 11 \mathrm{~b}+)$ cells were obtained from 6-8 pathogen-free female BALB/c mice lungs as described before [32]. Briefly, single cell suspensions $(0.5 \%$ BSA, $2 \mathrm{mM}$ EDTA, in 1xPBS) obtained from digested murine lungs (with collagenase D ( $1 \mathrm{mg} / \mathrm{ml}$; Gibco) was passed through a $30 \mu \mathrm{m}$ filter. CD11b microbeads and a LS positive selection column (MiltenyiBiotec) were used to purify CD11b + cells. The purified cells were confirmed by Trypan blue viability assay and more than $95 \%$ of them were viable. L929 cell (conditioned $30 \% \mathrm{v} / \mathrm{v}$ ) medium was used to maintain the purified cells at $37{ }^{\circ} \mathrm{C}$ in $5 \% \mathrm{CO}_{2}$. The cells were washed with PBS to remove non-adherent cells before used for virus infection. The NP, F4/80-FITC and CD11b antibodies were purchased from Chemicon, Biolegend and MiltenyiBiotec respectively. Cells were infected with each virus using a MOI of 5 .

\section{Immunofluorescence (IF) microscopy}

The cells were on $13 \mathrm{~mm}$ cover slides and treated with 4\% paraformaldehyde in PBS prior to permeabilization using $0.1 \%$ triton $\mathrm{X} 100$ in PBS. The cells were then stained with primary anti-NP antibody and FITC conjugated anti-mouse secondary antibody (IgG). The stained cells were mounted on slides using Citifluor and examined using Nikon eclipse 80i fluorescent microscope.

\section{Cytokine protein assay}

Supernatant both from mock-infected or virus-infected PMФ was obtained and centrifuged at 10,000 $\mathrm{g}$ for $10 \mathrm{~min}$ at $4{ }^{\circ} \mathrm{C}$ and the refined supernatant was used for cytokine assay. The cytokines in the supernatant were analyzed according to the Bio-Plex protein array system using the Bio-Plex mouse cytokine 23-plex panel (1x96 -well, \#M60009RDPD, Bio-Rad).

\section{Microarray analysis}

PMФ were either mock-infected or virus-infected and at 2 and 24hpi (in H1N1/WSN and H5N2/F118) and 24hpi (H5N3) the cells were harvested at $4{ }^{\circ} \mathrm{C}$ using RNA later (Ambion) in PBS buffer, and stored at $-80{ }^{\circ} \mathrm{C}$. Three independent experiments were performed for each time point and virus infections. RNeasy mini kit (Qiagen) was used to extract total RNA and double-stranded cDNA was synthesized from $3 \mu \mathrm{g}$ of total RNA using the GeneChip One-Cycle cDNA synthesis kit (Invitrogen, Affymetrix). Biotin-labelled cRNA was then synthesized using the GeneChip IVT labelling kit (Affymetrix). After cRNA fragmentation, $15 \mu \mathrm{g}$ of labelled cRNA was hybridized to the GeneChip Mouse Genome 430 2.0Array (Affymetrix). The arrays were scanned with GeneChip scanner3000 (Affymetrix) after they were washed and stained using the GeneChip Fluidics Station 450 (Affymetrix). Affymetrix.CEL files were generated from GeneChip Operating Software (GCOS) and imported to AltAnalyze 2.1.0 for analysis [97]. Proper quality control and normalization were performed in accordance with the AltAnalyze for Affymetrix.CEL files. The mean expression for each biological group and mean detection above background probabilities were calculated for each feature (probe). Expression values were calculated if the mean expression and the mean detection above background probabilities for at least one group meet expression thresholds, expression $>70$ and $p$-value $<0.05$. Differentially expressed genes (DEGs) 
or probe sets were selected with statistical significant change (P-value of the student's t-test (raw p-value), ANOVA and the Benjamini-Hochberg False Discovery method (adjusted p-value) $<0.05$ ) and $\mid$ Log Fold change $(\mathrm{FC}) \mid>1$ (Changes in virus infection in respect to corresponding mock). In the case where a gene is represented by multiple differentially expressed probe sets, the probe with maximum $\log \mathrm{FC}$ value was selected to construct heat maps. The number of DEGs was determined after summarizing the gene symbols of the differentially expressed using a customized Perl script (by removing redundancies). Venn diagrams showing the overlap of genes in different groups was performed using Venny 2.1 [98]. Functional annotation and pathway enrichment analysis were performed using Metascape (http://metascape.org/ gp/index.html\#/main/step1) [35] and q-value $<0.05$ was used to select statistically significant pathways. The data discussed in this publication have been deposited in NCBI's Gene Expression Omnibus [99] and are accessible through GEO Series accession number GSE86446

(https://www.ncbi.nlm.nih.gov/geo/query/acc.cgi?token= exkdcksmdhylbcn\&acc=GSE86446). Unsupervised hierarchical clustering was used to cluster the DEGs using Gene Cluster version 3 [100].

\section{Additional files}

Additional file 1: Figure S1. A) Identification of $P M \Phi$ using ant-F4/80 antibody and ant-CD11b antibody. B) FACS analysis of anti-CD11b and anti-F4/80 stained PMФ. C) Overlap analysis of DEGs in three IAV viruses and RSV (the data for RSV was obtained from our previously published work (Ravi et al., 2013)). D) Top 20 significantly enriched pathways of DEGs in IAVs and RSV infected PMФ. E) Unsupervised hierarchical clustering of DEGs at 2 and 24hpi in H1N1MSN and H5N2 infections. (PDF $230 \mathrm{~kb}$ )

Additional file 2: List of differentially expressed probe sets or genes $\mathbf{A}$ ) List of all DEGs with $\log ^{F C}$ and adjusted $p$-values $\mathbf{B}$ ) Expression levels of cytokines in H5N3 compared to H1N1/WSN and H5N2 C) Cytokine expression levels in H5N3 and RSV. (XLSX $233 \mathrm{~kb}$ )

\begin{abstract}
Abbreviations
DEGs: Differentially expressed genes; HA: Hemagglutinin; HPAl: Highly pathogenic avian influenza; hpi: Hours post-infection; IAV: Influenza A virus; ISGs: Interferon-stimulated genes; KEGG: Kyoto Encyclopedia of Genes and Genomes; LPAl: Low pathogenic avian influenza; LRT: low respiratory tract; M1: Macrophages activated by bacterial lipopolysaccharides (LPS) or IFNץ; M2: Macrophages activated by IL-4, IL-13 or TGF $\beta$; MOI: Multiplicity of infection; NP: Nucleoprotein of Influenza A virus; PMФ: Primary murine lung macrophages; URT: Upper respiratory tract
\end{abstract}

\section{Acknowledgments}

We thank Dawn Yeo (DSO National laboratories, Singapore), Li Liang (SMART) and Richard Sutejo (NTU) for technical assistance.

\section{Funding}

We thank Singapore-MIT Alliance for Research and Technology (NRF, Singapore), National Medical Research Council (Singapore), DSO National Laboratories (Singapore) and Bioinformatics Institute, (A*STAR) for funding support. Biruhalem Taye was awarded a Singapore International Graduate Award (SINGA) scholarship ( $A^{*}$ STAR, Singapore), and Chen Hui and Myint Zu Myaing were awarded Nanyang Technological University Scholarships (Ministry of Education, Singapore).

\section{Availability of data and materials}

The raw microarray datasets supporting the conclusion of this article have been deposited in [NCBl's Gene Expression Omnibus [99]] and are accessible through [GEO Series accession number GSE86446 (https://www.ncbi.nlm.nih.gov/geo/ query/acc.cgi?token=exkdcksmdhylbcn\&acc=GSE86446)].

\section{Authors' contributions}

BT and $\mathrm{CH}$ analyzed results of the microarray data. BT contributed other bioinformatics analysis, interpreted the data, and drafted the manuscript. MZM performed experimental procedures involving viruses and hybridizations. SMS helped in data analysis, drafting and critical review of the manuscript. RJS and BHT conceived the study, participated in experimental design and works and critically reviewed the drafted manuscript. All authors read and approved the final manuscript.

Competing interests

The authors declared that they have no competing interest.

\section{Consent for publication}

Not applicable.

\section{Ethics approval}

The study protocol was ethically approved by the Institutional Animal Care and Use Committee, National University of Singapore (Approved Protocol Number: 046/09). All animal experiments were conducted in accordance with Guidelines for the Care and Use of Animals for Scientific Purposes of the National Advisory Committee for Laboratory Animal Research (NACLAR), Singapore. All efforts were made to minimize animal suffering and BALB/C mice lungs were obtained after euthanasia by $\mathrm{CO}_{2}$ inhalation.

\section{Publisher's Note}

Springer Nature remains neutral with regard to jurisdictional claims in published maps and institutional affiliations.

\section{Author details}

${ }^{1}$ Bioinformatics Institute, A*STAR, 30 Biopolis Street \#07-01, Matrix, Singapore 138671, Republic of Singapore. ${ }^{2}$ School of Biological Science, Nanyang Technological University, 60 Nanyang Drive, Singapore 637551, Republic of Singapore. ${ }^{3}$ Aklilu Lemma Institute of Pathobiology, Addis Ababa University, Addis Ababa, P.O.BOX 1176, Ethiopia. ${ }^{4}$ Detection and Diagnostics Laboratory, Defence Science Organisation National Laboratories, 27 Medical Drive, Singapore 117510, Republic of Singapore. ${ }^{5}$ LKC School of Medicine, Nanyang Technological University, 50 Nanyang Ave, Singapore 639798, Republic of Singapore. ${ }^{6}$ National Public Health Laboratory, Ministry of Health, Singapore, Republic of Singapore. ${ }^{7}$ Department of Biological Sciences, National University of Singapore, 8 Medical Drive, Singapore 117597, Republic of Singapore. ${ }^{8}$ Current address Genome Institute of Singapore, A*STAR, 60 Biopolis Street, \#02-01, Genome, Singapore 138672, Republic of Singapore.

Received: 2 November 2016 Accepted: 17 May 2017

Published online: 30 May 2017

\section{References}

1. Medina RA, García-Sastre A. Influenza A viruses: new research developments. Nat Rev Microbiol. 2011;9:590-603.

2. McCaughey C. Influenza: a virus of our times. Ulster Med J. 2010;79(2):46-51.

3. Samji T. Influenza a: understanding the viral life cycle. Yale J Biol Med. 2009:82(4):153-9.

4. Fraaij PLA, Osterhaus ADM. The epidemiology of influenza viruses in humans. In: Hot Topics in Respiratory Medicine. 2010;(13):7-14.

5. Simonsen L, Viboud C, Taylor RJ, Miller MA. The epidemiology of influenza and its control. In: Birkhauser Advances in Infectious Diseases. 2011: 27-54

6. Dawood FS, Iuliano AD, Reed C, Meltzer MI, Shay DK, Cheng PY, Bandaranayake D, Breiman RF, Brooks WA, Buchy P, et al. Estimated global mortality associated with the first 12 months of 2009 pandemic influenza A H1N1 virus circulation: A modelling study. Lancet Infect Dis. 2012;12(9):687-95.

7. Simonsen L, Spreeuwenberg P, Lustig R, Taylor RJ, Fleming DM, Kroneman M, Van Kerkhove MD, Mounts AW, Paget WJ, Echenique H et al. Global Mortality Estimates for the 2009 Influenza Pandemic from the GLaMOR Project: A Modeling Study. PLoS Med. 2013;10(11):e1001558. 
8. Michiels B, van Puyenbroeck K, Verhoeven V, Vermeire E, Coenen S. The Value of Neuraminidase Inhibitors for the Prevention and Treatment of Seasonal Influenza: A Systematic Review of Systematic Reviews. PloS one. 2013;8(4):e60348.

9. Muthuri SG, Venkatesan S, Myles PR, Leonardi-Bee J, Al Khuwaitir TS, Al Mamun A, Anovadiya AP, Azziz-Baumgartner E, Baez C, Bassetti M, et al. Effectiveness of neuraminidase inhibitors in reducing mortality in patients admitted to hospital with influenza A H1N1pdm09 virus infection: a metaanalysis of individual participant data. Lancet Respir Med. 2014;2(5):395-404.

10. Beigel JH, Farrar J, Han AM, Hayden FG, Hyer R, De Jong MD, Lochindarat S, Tien NTK, Hien NT, Hien TT, et al. Avian influenza A (H5N1) infection in humans. N Engl J Med. 2005;353(13):1374-85.

11. Neumann G, Noda T, Kawaoka Y. Emergence and pandemic potential of swine-origin H1N1 influenza virus. Nature. 2009;459(7249):931-9.

12. Reperant LA, Kuiken T, Osterhaus ADME. Adaptive pathways of zoonotic influenza viruses: From exposure to establishment in humans. Vaccine. 2012;30(30):4419-34.

13. Richard M, De Graaf M, Herfst S. Avian influenza A viruses: From zoonosis to pandemic. Futur Virol. 2014;9(5):513-24.

14. Lindh E, Ek-Kommonen C, Väänänen VM, Vaheri A, Vapalahti O, Huovilainen A. Molecular epidemiology of H9N2 influenza viruses in Northern Europe. Vet Microbiol. 2014;172(3-4):548-54.

15. Cumulative number of confirmed human cases for avian influenza $A(H 5 N 1)$ reported to WHO, 2003-2015. In.; 2015.

16. WHO RISK ASSESSMENT of Human infections with avian influenza A(H7N9) virus. In.; 2015.

17. Munster VJ, Schrauwen EJA, De Wit E, Van Den Brand JM, Bestebroer TM, Herfst S, Rimmelzwaan GF, Osterhaus AD, Fouchier RA. Insertion of a multibasic cleavage motif into the hemagglutinin of a low-pathogenic avian influenza H6N1 virus induces a highly pathogenic phenotype. J Virol. 2010;84(16):7953-60

18. Stech O, Veits J, Weber S, Deckers D, Schröer D, Vahlenkamp TW, Breithaupt A, Teifke J, Mettenleiter TC, Stech J. Acquisition of a polybasic hemagglutinin cleavage site by a low-pathogenic avian influenza virus is not sufficient for immediate transformation into a highly pathogenic strain. J Virol. 2009;83(11):5864-8

19. Thangavel RR, Bouvier NM. Animal models for influenza virus pathogenesis, transmission, and immunology. J Immunol Methods. 2014;410:60-79.

20. Ilyushina NA, Khalenkov AM, Seiler JP, Forrest HL, Bovin NV, Marjuki H, Barman S, Webster RG, Webby RJ. Adaptation of pandemic H1N1 influenza viruses in mice. J Virol. 2010;84(17):8607-16.

21. Sakabe S, Ozawa M, Takano R, Iwastuki-Horimoto K, Kawaoka Y. Mutations in PA, NP, and HA of a pandemic (H1N1) 2009 influenza virus contribute to its adaptation to mice. Virus Res. 2011;158(1-2):124-9.

22. Mänz B, Schwemmle M, Brunotte L. Adaptation of avian influenza a virus polymerase in mammals to overcome the host species barrier. J Virol. 2013:87(13):7200-9.

23. Schrauwen EJA, Fouchier RAM. Host adaptation and transmission of influenza A viruses in mammals. Emerging Microbes Infections. 2014; 3(2):e9.

24. Murray PJ, Allen JE, Biswas SK, Fisher EA, Gilroy DW, Goerdt S, Gordon S, Hamilton JA, Ivashkiv LB, Lawrence T, et al. Macrophage activation and polarization: nomenclature and experimental guidelines. Immunity. 2014:41(1):14-20

25. Pearce EL, Pearce EJ. Metabolic pathways in immune cell activation and quiescence. Immunity. 2013;38(4):633-43.

26. A-González N, Castrillo A. Liver $X$ receptors as regulators of macrophage inflammatory and metabolic pathways. Biochim Biophys Acta. 2011; 1812(8):982-94

27. Nicol MQ, Dutia BM. The role of macrophages in influenza A virus infection. Futur Virol. 2014;9(9):847-62.

28. Lee SMY, Dutry I, Malik Peiris JS. Editorial: Macrophage heterogeneity and responses to influenza virus infection. J Leukoc Biol. 2012;92(1):1-4.

29. Pawelek KA, Dor D, Jr., Salmeron C, Handel A. Within-host models of high and low pathogenic influenza virus infections: The role of macrophages. PloS one. 2016;11(2):e0150568.

30. Sutejo R, Yeo DS, Myaing MZ, Hui C, Xia J, Ko D, Cheung PCF, Tan BH, Sugrue RJ. Activation of type I and III interferon signalling pathways occurs in lung epithelial cells infected with low pathogenic avian influenza viruses. PloS one. 2012;7(3):e33732.

31. Yeo DSY, Ng SH, Liaw CW, Ng LM, Wee EJH, Lim EAS, Seah SLK, Wong WK Lim CW, Sugrue RJ, et al. Molecular characterization of low pathogenic avian influenza viruses, isolated from food products imported into Singapore. Vet Microbiol. 2009;138(3-4):304-17.

32. Ravi LI, Li L, Sutejo R, Chen H, Wong PS, Tan BH, Sugrue RJ. A systems-based approach to analyse the host response in murine lung macrophages challenged with respiratory syncytial virus. BMC Genomics. 2013;14:190.

33. Josset L, Textoris J, Loriod B, Ferraris O, Moules V, Lina B, N'Guyen C, Diaz JJ, Rosa-Calatrava M. Gene expression signature-based screening identifies new broadly effective influenza A antivirals. PloS one. 2010;(10):e13169.

34. Andres-Terre M, McGuire HM, Pouliot Y, Bongen E, Sweeney TE, Tato CM, Khatri P. Integrated, Multi-cohort Analysis Identifies Conserved Transcriptional Signatures across Multiple Respiratory Viruses. Immunity. 2015;43(6):1199-211.

35. Metascape: A Gene Annotation and Analysis Resource. http://metascape. org/gp/index.html\#/main/step1.Accesed 20 Aug 2016.

36. Iwasaki A, Pillai PS. Innate immunity to influenza virus infection. Nat Rev Immunol. 2014;14(5):315-28.

37. Stifter SA, Bhattacharyya N, Pillay R, Florido M, Triccas JA, Britton WJ, Feng CG. Functional interplay between type I and II interferons is essential to limit influenza a virus-induced tissue inflammation. PLoS Pathog. 2016;12(1):e1005378.

38. Blackwell TS, Hipps AN, Yamamoto Y, Han W, Barham WJ, Ostrowski MC, Yull FE, Prince LS. NF-kappaB signaling in fetal lung macrophages disrupts airway morphogenesis. J Immunol. 2011;187(5):2740-7.

39. Sutejo R, Yeo DS, Myaing MZ, Hui C, Xia J, Ko D, Cheung PC, Tan BH, Sugrue RJ. Activation of type I and III interferon signalling pathways occurs in lung epithelial cells infected with low pathogenic avian influenza viruses. PLoS One. 2012;7(3):e33732.

40. Ensan S, Li A, Besla R, Degousee N, Cosme J, Roufaiel M, Shikatani EA, El-Maklizi M, Williams JW, Robins L, et al. Self-renewing resident arterial macrophages arise from embryonic CX3CR1 + precursors and circulating monocytes immediately after birth. Nat Immunol. 2016;17(2):159-68.

41. Schoggins JW, Rice CM. Interferon-stimulated genes and their antiviral effector functions. Current opinion in virology. 2011;1(6):519-25.

42. Chawla-Sarkar M, Lindner DJ, Liu YF, Williams BR, Sen GC, Silverman RH, Borden EC. Apoptosis and interferons: role of interferon-stimulated genes as mediators of apoptosis. Apoptosis. 2003:8(3):237-49.

43. Nordmann A, Wixler L, Boergeling Y, Wixler V, Ludwig S. A new splice variant of the human guanylate-binding protein 3 mediates anti-influenza activity through inhibition of viral transcription and replication. FASEB J. 2012;26(3):1290-300.

44. Lubeseder-Martellato C, Guenzi E, Jörg A, Töpolt K, Naschberger E, Kremmer E, Zietz C, Tschachler E, Hutzler P, Schwemmle M, et al. Guanylate-binding protein-1 expression is selectively induced by inflammatory cytokines and is an activation marker of endothelial cells during inflammatory diseases. Am J Pathol. 2002;161(5):1749-59.

45. Pichlmair A, Lassnig C, Eberle CA, Górna MW, Baumann CL, Burkard TR, Búrckstúmmer T, Stefanovic A, Krieger S, Bennett KL, et al. IFIT1 is an antiviral protein that recognizes 5 '-triphosphate RNA. Nat Immunol. 2011;12(7):624-30.

46. Pinto AK, Williams GD, Szretter KJ, White JP, Proença-Módena JL, Liu G, Olejnik J, Brien JD, Ebihara H, Mühlberger $\mathrm{E}$, et al. Human and murine IFIT1 proteins do not restrict infection of negative-sense RNA viruses of the orthomyxoviridae, Bunyaviridae, and filoviridae families. J Virol. 2015;89(18):9465-76.

47. Li HT, Su YP, Cheng TM, Xu JM, Liao J, Chen JC, Ji CY, Ai GP, Wang JP. The interaction between interferon-induced protein with tetratricopeptide repeats-1 and eukaryotic elongation factor-1A. Mol Cell Biochem. 2010;337(1-2):101-10.

48. Sedger LM, McDermott MF. TNF and TNF-receptors: From mediators of cell death and inflammation to therapeutic giants - past, present and future. Cytokine Growth Factor Rev. 2014;25(4):453-72.

49. McNelis JC, Olefsky JM. Macrophages, immunity, and metabolic disease. Immunity. 2014;41(1):36-48.

50. Biswas SK, Mantovani A. Orchestration of metabolism by macrophages. Cell Metab. 2012;15(4):432-7.

51. Zhu L, Zhao Q, Yang T, Ding W, Zhao Y. Cellular metabolism and macrophage functional polarization. Int Rev Immunol. 2015;34(1):82-100.

52. Kelly B, O'Neill LA. Metabolic reprogramming in macrophages and dendritic cells in innate immunity. Cell Res. 2015;25(7):771-84.

53. Galvan-Pena S, O'Neill LA. Metabolic reprograming in macrophage polarization. Front Immunol. 2014;5:420 
54. Haschemi A, Kosma P, Gille L, Evans CR, Burant CF, Starkl P, Knapp B, Haas R, Schmid JA, Jandl C, et al. The sedoheptulose kinase CARKL directs macrophage polarization through control of glucose metabolism. Cell Metab. 2012;15(6):813-26.

55. Stegemann-Koniszewski S, Jeron A, Gereke M, Geffers R, Kröger A, Gunzer M, Bruder D. Alveolar type II epithelial cells contribute to the anti-influenza A virus response in the lung by integrating pathogenand microenvironmentderived signals. mBio. 2016;7(3). doi:10.1128/mBio.00276-16.

56. Waithman J, Mintern JD. Dendritic cells and influenza A virus infection. Virulence. 2012;3(7):603-8.

57. Pulendran B, Maddur MS. Innate immune sensing and response to influenza. Curr Top Microbiol Immunol. 2015;386:23-71.

58. Graham AC, Temple RM, Obar JJ. Mast cells and influenza a virus: association with allergic responses and beyond. Front Immunol. 2015;6:238.

59. Ivan FX, Rajapakse JC, Welsch RE, Rozen SG, Narasaraju T, Xiong GM, Engelward BP, Chow VT. Differential pulmonary transcriptomic profiles in murine lungs infected with low and highly virulent influenza H3N2 viruses reveal dysregulation of TREM1 signaling, cytokines, and chemokines. Functional \& integrative genomics. 2012;12(1):105-17.

60. Rosseau S, Hocke A, Mollenkopf H, Schmeck B, Suttorp N, Kaufmann SHE, Zerrahn J. Comparative transcriptional profiling of the lung reveals shared and distinct features of Streptococcus pneumoniae and influenza A virus infection. Immunology. 2007;120(3):380-91.

61. Qiu X, Wu S, Hilchey SP, Thakar J, Liu ZP, Welle SL, Henn AD, Wu H, Zand MS. Diversity incompartmental dynamics of gene regulatory networks: The immune response in primary influenza a infection in mice. PloS one. 2015; 10(9):e0138110.

62. Boon ACM, Finkelstein D, Zheng M, Liao G, Allard J, Klumpp K, Webster R, Peltz G, Webby RJ. H5N1 influenza virus pathogenesis in genetically diverse mice is mediated at the level of viral load. mBio. 2011;2(5):pii:e00171-11.

63. Boon ACM, DeBeauchamp J, Hollmann A, Luke J, Kotb M, Rowe S, Finkelstein D, Neale G, Lu L, Williams RW, et al. Host genetic variation affects resistance to infection with a highly pathogenic $\mathrm{H} 5 \mathrm{~N} 1$ influenza A virus in mice. J Virol. 2009;83(20):10417-26.

64. Morrison J, Josset L, Tchitchek N, Chang J, Belser JA, Swayne DE, PantinJackwood MJ, Tumpey TM, Katze MG. H7N9 and other pathogenic avian influenza viruses elicit a three-pronged transcriptomic signature that is reminiscent of 1918 influenza virus and is associated with lethal outcome in mice. J Virol. 2014,88(18):10556-68.

65. Go JT, Belisle SE, Tchitchek N, Tumpey TM, Ma W, Richt JA, Safronetz D, Feldmann H, Katze MG.2009 pandemic H1N1 influenza virus elicits similar clinical course but differential host transcriptionalresponse in mouse, macaque, and swine infection models. BMC genomics. 2012;13:627. doi:10. 1186/1471-2164-13-627.

66. van Riel D, Leijten LME, van der Eerden M, Hoogsteden HC, Boven LA, Lambrecht BN, Osterhaus ADME, Kuiken T. Highly pathogenic avian influenza virus $\mathrm{H} 5 \mathrm{~N} 1$ infects alveolar macrophages without virus production or excessive TNF-alpha induction. PLoS Pathogens. 2011; 7(6):e1002099.

67. Cheung CY, Poon LLM, Lau AS, Luk W, Lau YL, Shortridge KF, Gordon S, Guan Y, Peiris JSM. Induction of proinflammatory cytokines in human macrophages by influenza A (H5N1) viruses: A mechanism for the unusual severity of human disease? Lancet. 2002;360(9348):1831-7.

68. Brandes M, Klauschen F, Kuchen S, Germain RN. XA systems analysis identifies a feedforward inflammatory circuit leading to lethal influenza infection. Cell. 2013;154(1):X197-212.

69. Tate MD, Schilter HC, Brooks AG, Reading PC. Responses of mouse airway epithelial cells and alveolar macrophages to virulent and avirulent strains of influenza a virus. Viral Immunol. 2011;24(2):77-88.

70. Lin KL, Suzuki Y, Nakano H, Ramsburg E, Gunn MD. CCR2+ monocytederived dendritic cells and exudate macrophages produce influenzainduced pulmonary immune pathology and mortality. J Immunol. 2008; 180(4):2562-72

71. Herold S, Steinmueller M, Von Wulffen W, Cakarova L, Pinto R, Pleschka S, Mack M, Kuziel WA, Corazza N, Brunner T, et al. Lung epithelial apoptosis in influenza virus pneumonia: The role of macrophage-expressed TNF-related apoptosis-inducing ligand. J Exp Med. 2008;205(13):3065-77.

72. Lee SMY, Gardy JL, Cheung CY, Cheung TKW, Hui KPY, Ip NY, Guan Y, Hancock REW, Malik PeirisJS. Systems-level comparison of host-responses elicited by avian $\mathrm{H} 5 \mathrm{~N} 1$ and seasonal H1N1 influenza viruses in primary human macrophages. PloS one. 2009;4(12):e8072.
73. Yu WCL, Chan RWY, Wang J, Travanty EA, Nicholls JM, Peiris JSM, Mason RJ, Chan MCW. Viral replication and innate host responses in primary human alveolar epithelial cells and alveolar macrophages infected with influenza H5N1 and H1N1 viruses. J Virol. 2011;85(14):6844-55.

74. Hui KPY, Lee SMY, Cheung CY, Ng IHY, Poon LLM, Guan Y, Ip NYY, Lau ASY, Peiris JSM. Induction of proinflammatory cytokines in primary human macrophages by influenza A virus $(\mathrm{H} 5 \mathrm{~N} 1)$ is selectively regulated by IFN regulatory factor 3 and p38 MAPK. J Immunol. 2009;182(2):1088-98.

75. Anikina AG, Shkurupii VA, Potapova OV, Kovner AV, Shestopalov AM. Expression of profibrotic growth factors and their receptors by mouse lung macrophages and fibroblasts under conditions of acute viral inflammation in influenza A/H5N1 virus. Bull Exp Biol Med. 2014;156(6):833-7.

76. Perrone LA, Plowden JK, García-Sastre A, Katz JM, Tumpey TM. H5N1 and 1918 pandemic influenza virus infection results in early and excessive infiltration of macrophages and neutrophils in the lungs of mice. PLoS Pathogens. 2008;4(8):e1000115.

77. Us D. Cytokine storm in avian influenza. Mikrobiyoloji Bulteni. 2008;42(2):365-80.

78. Szretter KJ, Gangappa S, Lu X, Smith C, Shieh WJ, Zaki SR, Sambhara S, Tumpey TM, Katz JM. Role of host cytokine responses in the pathogenesis of avian H5N1 influenza viruses in mice. J Virol. 2007;81(6):2736-44.

79. Chan RWY, Leung $\mathrm{CYH}$, Nicholls JM, Peiris JSM, Chan MCW. Proinflammatory Cytokine Response and Viral Replication in Mouse Bone Marrow Derived Macrophages Infected with Influenza H1N1 and H5N1 Viruses. PloS one. 2012;7(11): e51057.

80. Hang DTT, Song JY, Kim MY, Park JW, Shin YK. Involvement of NF-KB in changes of IFN- $\gamma$-induced CIITA/MHC-II and iNOS expression by influenza virus in macrophages. Mol Immunol. 2011;48(9-10):1253-62.

81. Cannon G, Callahan MA, Gronemus JQ, Lowy RJ. Early activation of MAP kinases by influenza A virus X-31 in murine macrophage cell lines. PloS one. 2014;9(8):e105385.

82. McKinney LC, Galliger SJ, Lowy RJ. Active and inactive influenza virus induction of tumor necrosis factor-a and nitric oxide in J774.1 murine macrophages: Modulation by interferon $-\gamma$ and failure to induce apoptosis. Virus Res. 2003;97(2):117-26.

83. To EE, Broughton BRS, Hendricks KS, Vlahos R, Selemidis S. Influenza A virus and TLR7 activation potentiate NOX2 oxidase-dependent ROS production in macrophages. Free Radic Res. 2014;48(8):940-7.

84. Wang J, Nikrad MP, Travanty EA, Zhou B, Phang T, Gao B, Alford T, Ito Y, Nahreini $P$, Hartshorn $K$ et al. Innate immune response of human alveolar macrophages during influenza a infection. PloS one. 2012;7(3):e29879.

85. Hoeve MA, Nash AA, Jackson D, Randall RE, Dransfield I. Influenza virus A infection of human monocyte and macrophage subpopulations reveals increased susceptibility associated with cell differentiation. PloSone. 2012; 7(1):e29443.

86. Monteerarat Y, Sakabe S, Ngamurulert S, Srichatraphimuk S, Jiamtom W, Chaichuen K, Thitithanyanont A, Permpikul P, Songserm T, Puthavathana P, et al. Induction of TNF-a in human macrophages by avian and human influenza viruses. Arch Virol. 2010;155(8):1273-9.

87. Österlund P, Pirhonen J, Ikonen N, Rönkkö E, Strengell M, Mäkelä SM, Broman M, Hamming OJ, Hartmann R, Ziegler T, et al. Pandemic H1N1 2009 influenza a virus induces weak cytokine responses in human macrophages and dendritic cells and is highly sensitive to the antiviral actions of interferons. J Virol. 2010;84(3):1414-22.

88. Ramírez-Martínez G, Cruz-Lagunas A, Jiménez-Alvarez L, Espinosa E, OrtízQuintero B, Santos-Mendoza T, Herrera MT, Canché-Pool E, Mendoza C, Bañales $J L$, et al. Seasonal and pandemic influenza H1N1 viruses induce differential expression of SOCS-1 and RIG-I genes and cytokine/chemokine production in macrophages. Cytokine. 2013;62(1):151-9.

89. Zhao C, Qi X, Ding M, Sun X, Zhou Z, Zhang S, Zen K, Li X. Pro-inflammatory cytokine dysregulation is associated with novel avian influenza a (H7N9) virus in primary human macrophages. J Gen Virol. 2016;97(2):299-305.

90. Zhou J, Law HKW, Cheung CY, Ng IHY, Peiris JSM, Lau YL. Differential expression of chemokines and their receptors in adult and neonatal macrophages infected with human or avian influenza viruses. J Infect Dis. 2006;194(1):61-70

91. Lay MK, Bueno SM, Gálvez N, Riedel CA, Kalergis AM. New insights on the viral and host factors contributing to the airway pathogenesis caused by the respiratory syncytial virus. Crit Rev Microbiol. 2016;42(5):800-12.

92. Van Drunen Littel-Van Den Hurk S, Watkiss ER. Pathogenesis of respiratory syncytial virus. Current opinion in virology. 2012;2(3):300-5. 
93. Short KR, Richard M, Verhagen JH, van Riel D, Schrauwen EJ, van den Brand JM, Manz B, Bodewes R, Herfst S. One health, multiple challenges: The interspecies transmission of influenza A virus. One health. 2015;1:1-13.

94. Wang W, Lu B, Zhou H, Suguitan Jr AL, Cheng X, Subbarao K, Kemble G, Jin $\mathrm{H}$. Glycosylation at $158 \mathrm{~N}$ of the hemagglutinin protein and receptor binding specificity synergistically affect the antigenicity and immunogenicity of a live attenuated H5N1 ANietnam/1203/2004 vaccine virus in ferrets. J Virol. 2010;84(13):6570-7.

95. Gabriel G, Dauber B, Wolff T, Planz O, Klenk HD, Stech J. The viral polymerase mediates adaptation of an avian influenza virus to a mammalian host. Proc Natl Acad Sci U S A. 2005;102(51):18590-5.

96. Zhao X, Dai J, Xiao X, Wu L, Zeng J, Sheng J, Su J, Chen X, Wang G, Li K. PI3K/Akt signaling pathway modulates influenza virus induced mouse alveolar macrophage polarization to M1/M2b. PloS one. 2014;9(8):e104506.

97. Emig D, Salomonis N, Baumbach J, Lengauer T, Conklin BR, Albrecht M. AltAnalyze and DomainGraph: analyzing and visualizing exon expression data. Nucleic Acids Res. 2010;38(Web Server issue):W755-762.

98. Oliveros JC. Venny. An interactive tool for comparing lists with Venn's diagrams. Access date Jan 2017.2007-2015.

99. Edgar R, Domrachev M, Lash AE. Gene Expression Omnibus: NCBI gene expression and hybridization array data repository. Nucleic Acids Res. 2002:30(1):207-10

100. de Hoon MJL, Imoto S, Nolan J, Miyano S. Open source clustering software. Bioinformatics. 2004:20(9):1453-4.

\section{Submit your next manuscript to BioMed Central and we will help you at every step:}

- We accept pre-submission inquiries

- Our selector tool helps you to find the most relevant journal

- We provide round the clock customer support

- Convenient online submission

- Thorough peer review

- Inclusion in PubMed and all major indexing services

- Maximum visibility for your research

Submit your manuscript at www.biomedcentral.com/submit 